\title{
Special Section Guest Editorial: Coastal Zone Remote Sensing for Environmental Sustainability
}

\author{
Shuisen Chen, ${ }^{\text {a }}$ Chandrasekar Nainarpandian, ${ }^{\text {b }}$ \\ and Ayad M. Fadhil Al-Quraishic \\ ${ }^{a}$ Guangdong Academy of Science, Guangzhou Institute of Geography, Guangzhou, China \\ ${ }^{\mathrm{b}}$ Manonmaniam Sundaranar University, Tamil Nadu, India \\ 'Tishk International University, Erbil, Iraq
}

Coastal zone refers to the area where the sea and land interact. The intertidal zone (tidal flat) is affected by tidal fluctuations and seawater every day, and a certain range of land and shallow sea on both sides of the sea-land transition zone. In recent years, various construction projects were performed around the coastal areas that resulted in coastal vulnerability due to erosion, accretion, and shoreline change, etc. Because of strong anthropogenic pressures and urbanization, coastal zones are already suffering ecological and biological stresses such as poor water quality, pollution, and the degradation or destruction of marine ecosystems.

New record severe weather, typhoons/hurricanes, fires, and floods are widely reported every year. The uncommon is becoming common; the unusual is turning to usual. The toll of these disaster events in financial costs, displacement of individuals, and loss of properties and lives is substantial and continues to rise as climate change, and human-induced activities generate more extreme weather and environment-related disaster events. Remote sensing of coastal environments advances the scientific understanding and application of technologies to address a variety of issues relating to sustainable development, including the status and change analysis of the coastal environment.

This special section promotes outstanding research concerning this aspect in the realm of remote sensing technology for coastal zone environment, focusing on state-of-the-art progress, developments, and new trends.

We accepted 16 papers by peer review, including image fusion quality assessment, coastal UAV radar signal simulation, satellite measurements of coastal ground displacement, coastline mapping accuracy estimation, island ecological evaluation and classification, island ecosystem service value assessment, beach mineral mapping, seawall mapping, seawater intrusion impact assessment under urbanization background, sea surface wind speed mapping, identification and classification of ships, remote sensing of temporal and spatial characteristics of harmful algae, monitoring of thermal emissions from nuclear power plants, involving radar (Tiangong-2) and optics (SPOT image, GF-1, GF-6, Orthomosaic, TM/ETM+/OLI/Hyperion, Sentinel-2) sensors, some of which involve big data analysis (such as remote sensing ecological index).

These 16 unique studies contributed innovative ways of harnessing active and passive remote sensing information as an efficient scientific means to address the impacts of coastal changes in various ways to, directly and indirectly, demonstrate problems involved in sustainable management of coastal development.

The authors, the reviewers, and the Journal of Applied Remote Sensing editorial team collectively contributed to making this peer-reviewed publication possible. As the guest editors, we want to acknowledge their efforts and show our appreciation for making it possible to share remote sensing technology to benefit society.

(1) 2022 Society of Photo-Optical Instrumentation Engineers (SPIE) 